\title{
Erratum to: A Prospective Randomized Trial of Enteral Nutrition After Thoracoscopic Esophagectomy for Esophageal Cancer
}

Tomoko Takesue, MD, Hiroya Takeuchi, MD, PhD, FACS, Masaharu Ogura, MD, PhD, Kazumasa Fukuda, PhD, Rieko Nakamura, MD, PhD, Tsunehiro Takahashi, MD, PhD, Norihito Wada, MD, PhD, Hirofumi Kawakubo, MD, PhD, and Yuko Kitagawa, MD, PhD

Department of Surgery, Keio University School of Medicine, Tokyo, Japan

ERRATUM TO: ANN SURG ONCOL (2015) 22:S802-S809

DOI 10.1245/S10434-015-4767-X

In the second sentence of the Results section in the abstract, there was an error in the results regarding the PN group. The corrected sentence is as follows:

The rate of weight loss at POD 14 was significantly lower in the EN group $(3.0 \pm 3.2 \%)$ than in the PN group $(5.1 \pm 3.7 \% ; p=0.020)$.

The online version of the original article can be found under doi:10. 1245/s10434-015-4767-x.

(C) Society of Surgical Oncology 2016

Published Online: 6 January 2016

H. Takeuchi, MD, PhD, FACS

e-mail: htakeuchi@a6.keio.jp 